\title{
${ }^{6}$ I continue to learn
}

\section{every day'}

How long have you worked in dentistry? Kate Quinlan invited followers on the BDJ Team Facebook page to reflect on their careers so far.

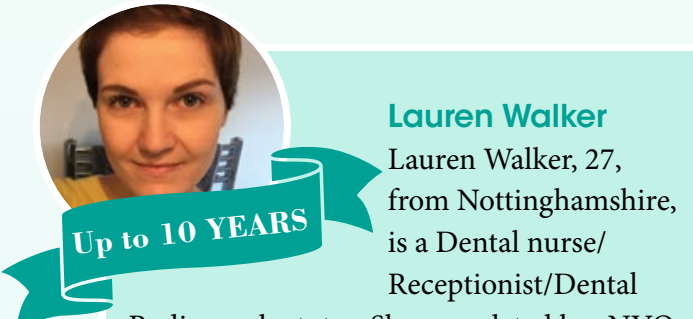

Radiography tutor. She completed her NVQ level 3 in dental nursing in 2012.

How did you get into dentistry? A dental nurse friend recommended the job and the practice.

What do you enjoy most about your role/ career? I love seeing patients every 6-8 weeks and seeing the huge improvements to their smiles. Working within orthodontics is very worthwhile; you are appreciated a lot more and there is overall a lot more job satisfaction. I also thoroughly enjoy taking radiographs within practice and helping other qualified dental nurses achieve their qualification in dental radiography.

If you could go back ten years and give some advice or tips to yourself, what would you say? I would say still gain your dental nurse qualification, but do your post qualifications earlier and apply for university to become a hygiene therapist!

What are you looking forward to in the next ten years? I look forward to continuing on my dental nurse journey, hopefully staying within orthodontics, and to continue helping nurses to gain their radiography qualification to enable them to enjoy their job as much as I do!

\section{Rebecca Silver}

Rebecca, 29, is a Specialist Dental Nurse in a private referral practice. She completed the National Certificate

in 2011 and Foundation Degree in Advanced Dental Nursing in 2018.

How did you get into dentistry? After moving to London after college I didn't have any idea about career prospects. I saw a job advert for dental nursing and after checking the job description it sounded like something I would enjoy, and the rest is history! That was in 2009 and since this time I have gained and learnt so much from a variety of colleagues and patients.

What do you enjoy most about your role/career? I enjoy the variety of treatment on offer as I find it interesting working with different specialists and providing treatments for patients. Every day is a school day and no two days are ever the same.

I also enjoy making a difference in patients' lives, no matter how small it may seem to other people. We can transform people's smiles and self-esteem and that really makes me feel like it's a job well done.

If you could go back ten years and give some advice or tips to yourself, what would you say? I would tell myself, in relation to dentistry, to take every opportunity you can. You never know when this could lead to something bigger. It also means that you never stop learning and this is what keeps the job interesting.

My general advice to myself would be to always ask; if you don't ask you won't get. The worse that could happen is that you are told no!

What are you looking forward to in the next ten years? I'm looking forward to completing my MSc in Advanced and Specialist Healthcare. I'm currently a second year student so just about to start my research project. I've done a back to back foundation degree and then a MSc so I'm also looking forward to a break from studying for a while. But I know that I will get bored so I'm sure the break will not last long. I am also looking forward to seeing where my career will take me, and how dental nurses will be utilised in the future!

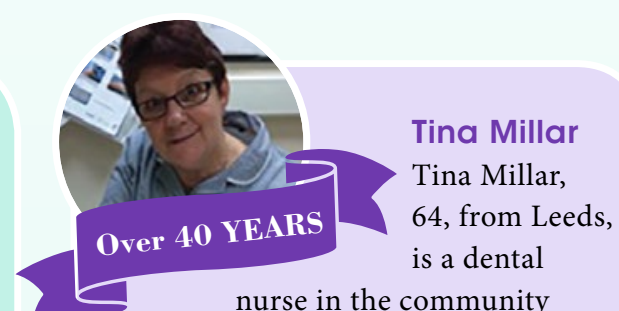

dental service who has been working in dentistry for 47 years.

How did you get into dentistry?

I started as a dental surgery assistant in 1975. In 1995 I became a sedation nurse after seeing a job advertised in the local paper. I was terrified of the dentist as a child so felt my role in dental sedation was ideal as I knew how patients were feeling and felt I could really be supportive towards them.

What do you enjoy most about your role/career? I feel I have been fortunate to work with some very inspirational people at Leeds Dental Institute and have loved the teaching part of my job, interacting with trainee dental nurses, dental students and postgraduate students. I also worked in the UAE Armed Forces for seven years as a dental nurse. I coordinated dental trials for toothpaste companies whilst working at the Dental Institute. I feel I have had a varied employment experience which has kept me interested in the job.

What are you looking forward to in the 2020s? I will be retiring at the end of July and look forward to spending every winter in the sun.

The photo was taken when Tina retired from working at the Dental Institute in sedation coordination to return to working in the community. We wish Tina all the best for her retirement! 
10-20 YEARS

\section{Deborah Williams}

Deborah, 37, has been a dental nurse for 16 years and qualified for ten years. She is a Special Care Dental Nurse in the community in Truro, Cornwall. She completed the National Certificate in Dental Nursing in 2009 and has also completed post-graduation NEBDN Certificates in sedation and in fluoride application.

How did you get into dentistry? I saw a job advertised in the Job Centre when I moved to Edinburgh from Cyprus (my exhusband was in the army). I used to like the dental nurses that looked after me when I was a child and so I thought 'I could do that'.

What do you enjoy most about your role/career? I enjoy working alongside special care patients getting them through their treatment whether it is IHS, IV or a general anaesthetic.

If you could go back 16 years and give some advice or tips to yourself, what would you say? Well, when I was younger I always wanted to be a 'proper nurse' but I didn't really want to go to university. But I have now bitten the bullet, so to speak, and have applied to possibly start in September... I am just hoping I get an interview.
What are you looking forward to in the next 16 years? Potentially qualifying as an adult nurse but if this doesn't happen, I will still be giving my role as a dental nurse my all as I love my job.

The photo shows Deborah in theatre on a special general anaesthetic day.

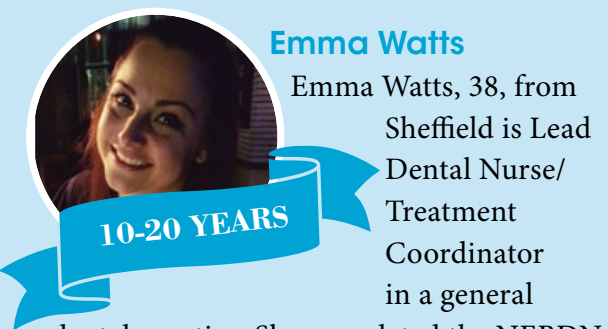

dental practice. She completed the NEBDN National Certificate in 2002, the British Dental Associate Certificate in Dental Radiography in 2013, and the NEBDN Certificate in Dental Implant Nursing 2017.

How did you get into dentistry? I 'fell into' dental nursing after leaving school. I was unsure what I wanted to do in the future so I took a job at my local dental practice as a dental nurse while I decided which career path I wanted to follow. I enjoyed dental nursing so much that I decided to stay in dentistry and began my NEBDN national certificate qualification soon after at my local dental hospital.

What do you enjoy most about your role/career? As a treatment coordinator,
I am able to be involved with patients throughout their treatment at the practice, which in the case of implant treatment may be several months. I am now able, under a dentist's prescription, to run my own clinics where I have time to chat to patients about their expectations, their desired results and how we can achieve them. I'm also able to use other practical skills such as impression taking, clinical photography and taking X-rays to help the patient's treatment run smoothly and efficiently. When a patient leaves the practice after completing their treatment feeling like they have the confidence to smile again, I take pleasure in knowing that I have played a part in their journey.

If you could go back 20 years and give yourself some advice or tips to yourself, what would you say? I would say take every opportunity and throw yourself into it $100 \%$. Don't fear making mistakes, or what other people think about you.

What are you looking forward to in the next 20 years? The role of the dental nurse has been developed so much in the past 20 years and I am excited to see how my role continues to develop over the next 20 years. On a more personal level I am considering moving towards becoming a dental nurse tutor, and I am looking at gaining a qualification to help me achieve my goal.

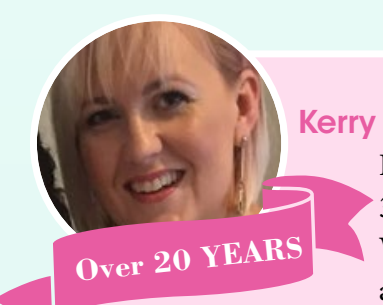

Birmingham, is a specialist dental nurse working in the community combined with a dental hospital. Kerry says: 'we are now our own specialist division of the community trust and are also a teaching trust'. She completed her NEBDN dental nursing qualification in 1998.

How did you get into dentistry? I did a week's work experience when in year 9 at senior school.

What do you enjoy most about your role/career? I enjoy how varied the role is and the flexibility this allows, and the reward of helping vulnerable adults to receive high quality and equal care. I also enjoy promoting our service to stakeholders and new teams.

If you could go back 20 years and give some advice or tips to yourself, what would you say? Someone should have told me that I could or should have gone to university!

What are you looking forward to in the next 20 years? I'm hoping to find a good work-life balance. Having busy 12 -yearold boy-girl twins and a very responsible role doesn't always work out. I'm looking forward to seeing how far my kids excel in their sports of football and gymnastics; after all this rushing around I'd like to think they will go far! I'd love to make that special trip to Australia and Italy. In my work life, I hope to have played a significant role in the awareness of autism and dementia within dentistry. I hope to achieve the Autism accredited mark for our service within the next two years!

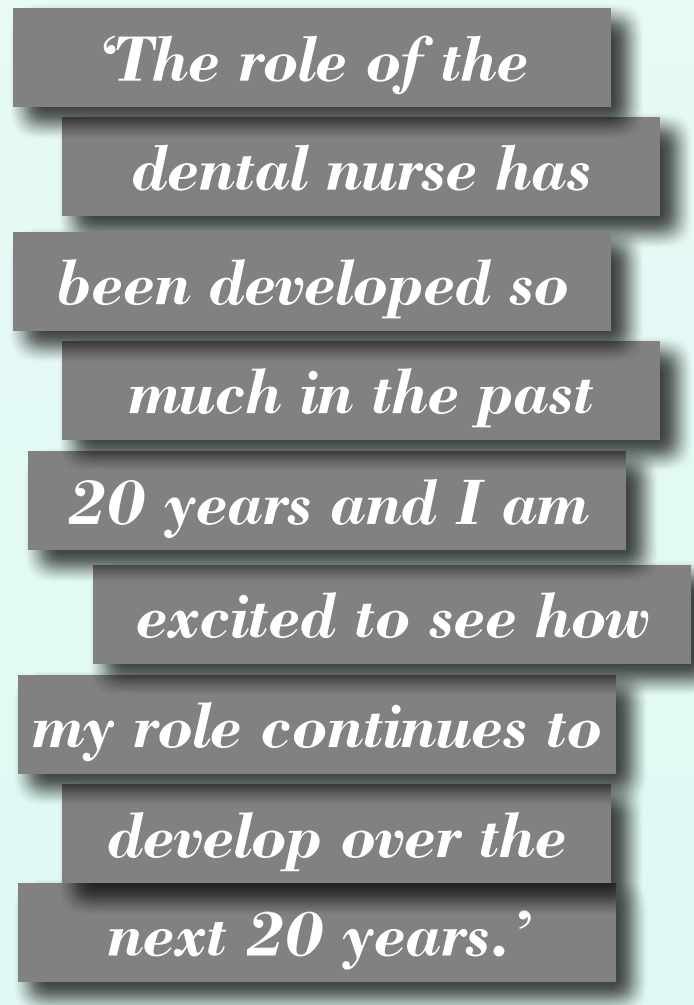


Lindsay 'Linz' O'Brien (Douglas)

Lindsay O'Brien,

38 , is a dental nurse working in the Bridge of Earn Dental

Practice in Bridge of Earn, a small town in Perthshire, Scotland. Linz started her career in Edinburgh and completed her NEBDN Certificate in Dental Nursing in 1999 and the BDA Radiography Certificate for dental nurses in 2014.

How did you get into dentistry? I completed my work experience at the practice my mum works at as practice manager in Liberton, Edinburgh in 1997. While there I was asked by Mr O'Donnell, the practice owner, if I would like to accept the position of dental nurse they had available from August that year - which I did. I was lucky to follow in my mum Alison's footsteps and start my career in dentistry working in the same practice as she did at my age, also starting as a dental nurse.

\section{What do you enjoy most about your} role/career? I love the interaction with the patients and the variations throughout the day, and also seeing families returning and seeing children grow up over the years. As I am currently based in a VT [vocational training] practice, I also love my position as the VT Dental Nurse. I feel that having 23 years' experience is very helpful when working with the newly qualified dentists, making them feel at ease and not having to worry about what else is going on around them. I have gained a vast amount of experience over the years, which I am confident in sharing and passing on to not only the VTs but to our other dentists and nurses. There is no element of dentistry I don't enjoy; the team I work with are all very supportive of each other. I enjoy having a hands-on approach to dentistry and I am not afraid to get 'stuck in' to any task thrown my way.

\section{If you could go back 20 years and give} some advice or tips to yourself, what would you say? Don't be afraid to ask questions; the only way you learn is by asking, no matter how simple or silly you think the question is, and you will find that most dentists are glad to give advice or explain things to you, especially when it means that you will work better and smoother as a clinical team. Also, don't think you will know everything after you qualify - over the 23 years I have worked
I am always learning things.

What are you looking forward to over the next 20 years? Continuing to work with the VT dentists and helping them in their first year out of university. I still keep in touch with a lot of the VTs I have worked with over the years and feel grateful when they contact me to 'just check they are doing something correctly' or are after a bit of advice on what to do or materials to use. I am also part of the RAF Air Cadets with 2345 Leuchars Squadron, where I am hoping to become a commissioned officer. I feel this will help me in my workplace too in gaining leadership skills and teaching skills, both transferable to help with training in practice with our in-house clinical skills sessions and also when training new staff. I love my dental nursing career and could not see myself doing any other job. To me, being a dental nurse is something I was born to do, especially as my mum was a dental nurse and advanced on to become a practice manager. I can honestly say I am looking forward to continuing working with my employer Declan Gilmore at Bridge of Earn Dental Practice within the vocational training element of the practice and seeing what the next 20 years hold in store for me.
Justine Claire Nicholls Justine Claire Nicholls, 50, from Hertford, is a dental hygienist in general practice. She completed the Guy's Certificate in Dental Surgery Assisting with Distinction and the Claudius Ash Gold Award in 1988, the National Certificate in 1988, and received the Diploma in Dental Hygiene in 1992 from Guy's Hospital with the Hu Friedy scaling award.

How did you get into dentistry? My grandmother hand painted pottery for Wedgwood; my aunty is an artist; the ladies in my family all sew and are very creative. I am lucky to have combined my manual dexterity, love of people and outgoing nature in my career. Knowing my strengths in my choice of role has resulted in a long, happy, successful career.

\section{What do you enjoy most about your}

role/career? The role is always rewarding and always challenging. I continue to learn every day. I enjoy finding solutions to break down barriers to oral health care, both in the profession and in individual patient care.

My role is balanced with family life.

I use my wealth of experience and knowledge to implement a holistic approach to oral care and overall wellbeing using my full scope of skills.

I enjoy involving, educating and inspiring others with presentations in schools and careers talks, showcasing the benefits of the work of dental hygienists and therapists.

If you could go back 30 years and give some advice to yourself, what would you say? I would advise myself to have a clear vision of personal development and as much positive mentoring as possible. Experience working in many different dental settings to gain a wider appreciation of the profession. Knowledge is power: try to empower yourself and your patients. Read, read, read ... stay updated through journals and social media in the profession. Join professional bodies such as BSDHT and the British Society of Periodontology. Communicate with other dental professionals as the role can be isolating.

What are you looking forward to in the 2020s? I am optimistic that the role of the DCP will continue to elevate with increased independence and greater access to improve dental care provision to our population, for example prescribing rights.

I look forward to further development in peri implant disease control and prevention.

I look forward to furthering our changing mindset to the planet and improving our practice regarding the future ecological impact of our progress in dentistry. 